\title{
Os outsiders do brega: corporeidade, estilo de vida e identidade bregueira em Belém, Pa
}

The outsiders of brega: corporeity, lifestile and bregueira identity in Belém, $\mathrm{Pa}$

Miguel de Nazaré Brito Picanço ${ }^{1}$ José Rogério Lopes ${ }^{2}$ 


\section{Resumo}

O artigo descreve e analisa os processos percorridos pela música brega, até se firmar em tecnobrega, na cidade de Belém (PA), e as mudanças que esses processos geraram no estilo bregueiro de seus adeptos. Desses processos, buscamos situar um conjunto de tensionamentos locais, ora centrados em gostos culturais, ora em estilos de vida, que produziram rotulações aos jovens bregueiros, os definindo como desviantes. No campo dessas tensões, analisamos os modos de produção de políticas de identidade que constituem quadros normatizadores da ação individual e coletiva desses sujeitos, quando associados a códigos corporais e de vestimenta.

Palavras-chave: Música brega; tecnobrega; estilo de vida; outsiders; políticas de identidade.

\section{Abstract}

The article describes and analyzes the processes driven by brega music, until you sign in tecnobrega in the city of Belém (PA), and the changes that these processes generated in brega style of its adherents. These processes, we seek to place a set of local tensions, now centered on cultural tastes, sometimes in lifestyles, which produced rotulações the young bregueiros, the defining as deviant. In the field of these tensions, we analyze the identity politics production methods that are standard-setting frameworks of individual and collective action of these subjects, when associated with bodily codes and dress.

Keywords: Brega music; tecnobrega; lifestile; outsiders; identity politics. 


\section{Introdução}

A cidade de Belém, no Pará, assistiu o desenvolvimento de um estilo musical, nas últimas décadas, denominado de Brega. Apesar de manifestar-se em outras cidades do Brasil, esse estilo musical ganhou em Belém uma conotação diferenciada, com produção local, em especial no ritmo, na maneira de dançar e, sobretudo, na relação que os belenenses estabelecem com a música, no cotidiano da cidade. Esses traços locais passaram a caracterizar aqueles que moram nas periferias da grande Belém, onde a música se manifesta pelas ruas, nos ônibus coletivos, nas lojas, feiras e, ainda, nas casas, chegando pelas ondas das rádios da cidade. Nos finais de semana, o estilo brega se espalha pelos bregões ${ }^{3}$ da cidade, tendo como principal instrumento de execução as aparelhagens, que promovem diversão e entretenimento aos adeptos do estilo musical.

A extensão e a intensidade de manifestações desse estilo musical na cidade já estão relacionadas à cultura popular musical de Belém (Costa, 2006; Picanço, 2004), retratando de diversas formas o cotidiano das periferias dessa cidade e estabelecendo uma proximidade entre esse estilo musical e os sujeitos que com ele se identificam, denominados de bregueiros. Portanto, ser bregueiro, em Belém, é ser adepto da música brega, o que também se expressa pelo jeito próprio de vestir e dançar nos bregões da cidade.

Buscando caracterizar a relação entre essas expressões culturais que convergem para a produção do estilo brega-bregueiro, em Belém, consideramos aqui algumas incursões etnográficas realizadas no circuito brega nas periferias da cidade, entre 2004 e 2010, além da experiência de morador da periferia da Grande Belém de um dos autores, que desde a infância conviveu com o universo bregueiro, ouvindo e dançando nos bregões da cidade.

Para tanto, este artigo é composto de duas sessões. Na primeira, fazemos uma breve descrição dos processos percorridos pela música brega, até se firmar em tecnobrega 4 , em Belém. Na segunda, dialogamos com teóricos que nos auxiliam a discutir a relação existente entre a música brega e a rotulação atribuída a esse estilo musical, alcançando os adolescentes e jovens que são adeptos da música e que são estigmatizados como outsiders. Entender a relação entre a identidade bregueira desses sujeitos e a condição de outsiders a ela associada implica, como veremos, em compreender a mediação operada pelos códigos corporais e de vestuário que compõem a sua performance (Santamaría, 2006).

\section{A música brega em Belém: histórias e significados}

O estilo musical brega se faz notar na cidade de Belém desde os anos 1970 e vem passando por várias fases. $O$ desenvolvimento do brega fixou uma marca regis-

\footnotetext{
3 Os bregões são denominações das casas de festas noturnas onde o entretenimento exclusivo é o estilo brega. Nesses espaços a música chega até os adeptos por meio das aparelhagens, um conjunto de equipamentos de alta potência sonora, dotado de tecnologia avançada, usado para executar a música e promover as festas de brega na cidade de Belém e no interior do estado.

4 Tecnobrega é uma "modalidade" da música brega que surgiu em Belém, a partir do ano 2000, e se consolidou na cidade entre os anos de 2009 e 2010 com a adesão dos jovens e adolescentes ao estilo musical.
} 
trada pelo seu estilo dançante, que se faz no jeito criativo dos bregueiros, materializado nas expressões corporais por eles exibidas nas festas e que conferem ao público uma identidade característica.

Segundo Costa (2007, p. 73), "Nos discursos que tratam da especificidade do brega paraense destaca-se a menção a um intercâmbio frequente com outros ritmos basicamente originários do universo musical latino-americano, ressaltando-se os [...] ritmos caribenhos". Caracterizado pela fusão de influências caribenhas e do nordeste brasileiro, além de outros estilos musicais, segundo o mesmo autor, o brega surge a partir dos processos de aculturação provocados por movimentos migratórios contínuos para a região amazônica, influenciado também pela Jovem Guarda.

Com o declínio da Jovem Guarda na década de 1970, surgem no cenário musical brasileiro novos representantes de diversos ritmos, que impulsionaram o aparecimento de outros estilos como o forró, a lambada, a música sertaneja e o axé music. É nesse contexto que surge a música brega em Belém.

Segundo Favacho (1995), o brega foi originalmente difundido nas cidades do interior do estado do Pará e só alguns anos depois migra para as periferias da capital paraense. Isso ocorreu em um período no qual Belém sofre profundas transformações, em especial na sua ocupação territorial, em decorrência de políticas públicas federais que incentivaram a ocupação da Amazônia, desencadeando forte movimento migratório de populações nordestinas, que adentram à região em busca de trabalho.

A decadência dessas políticas fomentou o êxodo rural na região e a cidade de Belém tornou-se o centro urbano mais atrativo para os migrantes, que buscam na sua região metropolitana melhores condições de sobrevivência.

Esse contexto de crise social, êxodo rural e desemprego possibilitam uma nova configuração urbana para a capital paraense, a saber: a formação das periferias e as ocupações do espaço urbano de Belém, que são marcadas por conflitos entre os migrantes e o Estado paraense que se encontrava desprovido de qualquer política pública habitacional. É a partir da configuração desse novo espaço urbano de Belém que a música brega vai se consolidar na capital, cujo público alvo é a população que compõe essa nova configuração espacial da cidade.

A partir de 1980, surgiu no Pará o primeiro movimento bregueiro. Nesse primeiro momento, a execução da música brega era restrita às rádios $\mathrm{AM}$ locais, enquanto que nas rádios FM a música não circulava, assim como não circulava nas casas de festas da capital, restando para o estilo as casas, as pessoas e as festas das periferias da cidade e do interior do Estado. Sem o apoio da grande mídia, o primeiro movimento bregueiro contava apenas com as aparelhagens, como instrumento de divulgação e execução de suas músicas.

No ano de 1995, outro movimento bregueiro se inicia. Agora, o brega aparece de cara nova, introduzindo nas músicas instrumentos como a guitarra, o contra baixo e a bateria, que até então não compunham o cenário bregueiro. Essa inovação impulsionou um ritmo acelerado à música, com notável utilização do $\mathrm{PIT}^{5}$ e inserção de mais guitarras. Eis que surge o brega Calypso.

5 PIT- Espécie de recurso tecnológico utilizado com o objetivo de acelerar o ritmo da música. 
A partir daí a música ganha novos adeptos, conquista novos espaços, como rádios FM e emissoras de televisão, com programas de até quatro horas exibindo especificamente cantores bregueiros. Nesse contexto, o brega chega também às casas de shows da capital e impulsiona a abertura de outras casas noturnas específicas para o público bregueiro. A partir de então, o estilo se expande para além das periferias e se instala de vez na capital paraense.

O estilo denominado originalmente de brega, nesse novo contexto passa a se chamar de Calypso e, posteriormente, de brega melody, depois brega pop. Nessas novas modalidades bregueiras, as letras e as músicas expõem uma pretensão a se tornarem massivas, isto porque sintetizam influências dos mais diversos estilos e adentram ao cenário musical nacional.

A partir do ano 2000, a música brega se consagra definitivamente como estilo musical tipicamente paraense, ao ser reconhecida nacionalmente como a música e o ritmo que embala o Pará. Esse novo movimento recebe, a partir do ano de 2009, a denominação de tecnobrega e, entre os anos de 2010 e 2011, tem como público alvo os jovens das capitais brasileiras, mas é com os jovens da capital paraense que o tecnobrega vai possibilitar o aparecimento de uma nova identidade bregueira ${ }^{6}$, onde a corporeidade manifesta-se como expressão daqueles que se auto identificam como bregueiros, seja nas coreografias que exigem movimentos corporais intensos e diversos como o Treme ${ }^{7}$, seja pelas roupas que vestem seus corpos, ou ainda, pelo corte de cabelo e pelo desenho da sobrancelha dos adeptos da música brega.

\section{Corpos, rótulos e identidade bregueira}

Segundo Picanço (2004), em geral, o vocábulo brega conota algo de estilo grosseiro, de mal gosto, sem beleza e sem refinamento. Brega seria, nessa perspectiva, o oposto daquilo que é requintado e chique. Dessas interpretações do termo, ao que ele representa no contexto musical de Belém, percebe-se certa diferenciação e acréscimo de significados, quando o sentido de brega se configura em um estilo musical que "caiu no gosto" popular dos belemenses.

Segundo Damasceno et al (2002), na Bahia, o significado atribuído à palavra brega tem configuração pejorativa, diz respeito a prostíbulo. $O$ autor especula que, no passado, uma rua de salvador, onde funcionavam alguns prostíbulos, recebeu o nome de Manoel da Nobrega, porém, com o tempo a placa onde estava escrito o nome da rua quebrou-se, restando apenas as duas últimas sílabas do sobrenome do padre-brega. Em consequência disso, as prostitutas frequentadoras dos locais também eram chamadas de bregueiras.

Percebe-se que o termo brega está atrelado historicamente a sentidos pejorativos e está intimamente relacionado com sujeitos tidos como marginais, ou àqueles que compõem a massa, o conjunto do corpo social.

\footnotetext{
6 A associação entre a música brega e a tecnologia das aparelhagens propicia a emergência de um contexto onde as identidades dos jovens, sobretudo, se propõem estar em sintonia com a modernidade, constituindo circuitos nos quais outras mediações tecnológicas tornam-se referentes identitários, como sugere Ergur (2009).

7 TREME é o nome dado à dança elaborada e executada individualmente por jovens e adolescentes nas festas de tecnobrega, promovidas por aparelhagens, cujos movimentos corporais se dão de maneira mais intensa envolvendo todo o corpo, em especial braços e cabeça, que se movimentam como se o corpo tremesse, daí o nome, Treme. A coreografia tem como característica provocar movimentos que remetem a um corpo tremendo.
} 
Essa projeção negativa que a palavra brega carrega também é conotada no estilo musical brega de Belém. Tal teor pejorativo historicamente tem marcado sujeitos, sejam eles quais forem, que estejam direta ou indiretamente relacionados à música brega, desde os cantores, os DJs de aparelhagens e, principalmente, os jovens que ouvem e dançam esse estilo musical.

A ideia de inferioridade concebida ao estilo musical deve-se principalmente à nomenclatura atribuída à música, sobretudo, na conotação que a palavra brega assumiria enquanto oposto a "chique" e a "elegância". Esse sentido pejorativo atribuído acabou por descaracterizar, banalizar e até marginalizar a cultura musical brega de Belém, em proveito de outras culturas musicais consideradas como "superiores" e de "bom gosto".

Isto ocorre, por exemplo, quando se faz comparações entre o brega e o carimbó $^{8}$, entre sujeitos do estado. Este último seria o estilo musical dos sujeitos pensantes e de sábias escolhas, enquanto que o primeiro estaria representado pelos sujeitos desprovidos do bom gosto e da capacidade de escolhas bem-feitas, que acabaram por ser rotulados como sujeitos marginais de Belém.

Aqui, estamos diante de uma discriminação que serve ao estabelecimento de um regime de valor, constituído nas tensões sociais entre tradições instituídas e movimentos instituintes da cultura paraense. As expressões costumeiramente expostas, nessas tensões locais entre os sujeitos, evidenciam que a utilização do termo gosto está relacionada a um estilo de vida que, segundo Bourdieu (1999), é a retradução de diferenças objetivamente inscritas nas condições de existência de segmentos sociais diferenciados. Tratar-se-ia, aqui, de expressões de gosto modesto ou gosto de luxo, segundo este autor, que remetem à definição social de distinções entre luxo e necessidade e às formas sociais de apropriação (como propensão ou aptidão desses segmentos) de produtos sociais ${ }^{9}$.

Há nesse discurso uma tentativa de inferiorizar o gosto musical dos bregueiros 10 e, neste caso, a escolha por determinados bens culturais funciona como marcador social, como marcador de classe e grupos sociais.

[...] a tendência é que os grupos sociais procurem classificar e ordenar suas situações sociais e usar os bens culturais como meio de demarcação, como comunicadores que estabelecem barreiras entre algumas pessoas e constroem pontes com outras. Esse foco nas utilizações sociais de bens culturais chama nossa atenção com firmeza para as práticas das pessoas reais que interpretam e tem necessariamente de fazer julgamentos a respeito dos outros, decodificando os signos culturais que os outros praticam, exibem e consomem (Featherstone, 1995, p.94).

Essa tentativa de classificar e ordenar situações sociais utilizando bens culturais como recurso de marcação e desqualificação de bens alheios foi observada pelos autores em situações onde o bem cultural em questão era a música brega.

8 O Carimbó é compreendido como um ritmo, uma música e uma dança folclórica do Pará.

9 Uma perspectiva complementar é aprendida desde Godelier (1969). Pensando esses gostos distintos como expressões de valores e de uma ordem hierárquica, quando a música brega é discriminada como um bem cultural desprovido do bom gosto, isto evidencia que "a hierarquia dos bens expressa, pois, a hierarquia dos valores ligados às diversas atividades sociais, e esses valores traduzem o papel dominante no seio da sociedade e de certas estruturas sociais" (Godelier, 1969, p. 79).

10 Por outro lado, a busca de inferiorização de um "gosto cultural" distinto se sustenta, também, na utopia de que o gosto característico de um grupo, ou segmento social, deveria ser hegemônico (Caldas, 1988). 
Citamos dois casos onde os discursos dos sujeitos desqualificam a música brega, mas em alguns momentos se apropriam dela. Por algumas vezes, ouvimos professores e intelectuais verbalizarem descontentamentos com esse estilo, dizendo que é música de péssimo gosto, sem letra, ou com letras sem um teor crítico e político, ou ainda, que não entendiam como alguém poderia gostar desse tipo de música.

O que inquietava nesses discursos era o fato de que existia certa dicotomia entre o dizer e o fazer, no sentido de que, por vezes, presenciamos e até acompanhamos algumas dessas pessoas em "bregões" da cidade, quando não, em festas cujo ritmo predominante era a música brega.

Uma dessas experiências ocorreu quando, em uma sexta-feira, ao sairmos da escola em que fazíamos observações de campo, um grupo de professores convidounos a acompanhá-los até um bar. Chegando lá, um dos professores pediu ao proprietário que colocasse música, no que o homem falou "só tem brega". Uma das professoras que nos acompanhava no grupo não hesitou em falar: "brega não é música".

Essa ambivalência em relação ao que é diferente e especialmente ao que é identificado com o povo, por parte daqueles que tomam para si e para os seus, a tarefa de catequizar o resto da sociedade, não decorre apenas do conhecimento de beleza, da eficácia e da adequação insuspeitada do que lhe é culturalmente alheio. $\mathrm{Na}$ verdade, essas atitudes contraditórias em relação à cultura popular resultam em grande medida do paradoxo [...] existente entre o saber e o fazer" (Arantes, 1990, p. 13).

Outra experiência dessa natureza ocorreu recentemente, no mês de fevereiro de 2015, quando coletávamos dados para esse estudo em uma delegacia de polícia da capital. Dialogávamos com a delegada Maria José Moraes, cuja condição de informante se deu pelo fato dela ter sido diretora da Divisão de Atendimento e Tratamento ao Adolescente do Pará, (DATA) em Belém, e, portanto, estar ligada aos casos de jovens e adolescentes infratores ${ }^{11}$. O objetivo da entrevista era saber se existia alguma relação desses atos infratores com os adolescentes e jovens bregueiros, como discutiremos mais adiante.

Por hora, o que interessa registrar aqui é a afirmação da delegada Maria José Moraes, em relação à discriminação e a rotulação do universo bregueiro.

Eu não consigo, por mais que eu tente, não consigo me desprender do preconceito que tenho do brega. Eu não ouço de jeito algum, não gosto da música, principalmente do Tecnobrega, do Treme. As músicas são horríveis. Às vezes eu até danço, quando vou em alguma festa que por casualidade toca a música brega, eu danço, mas é uma casualidade. Eu nunca fui a uma festa de brega a não ser para fechar a festa, quando havia necessidade (Maria José Moraes) ${ }^{12}$.

Essa visão pejorativa atribuída à música brega, enquanto um estilo marginal e desprovido de qualidade, sem teor crítico da realidade, foi também atribuída à Jovem Guarda, que, segundo Brandão (1990, p. 7),

11 Um dos traços componentes da identidade bregueira dos jovens, em Belém, é costumeiramente associado a infrações como furtos e outras formas de violência urbana.

12 Entrevista com Maria José Moraes concedida a Miguel de Nazaré Brito Picanço e José Rogério Lopes, em 1 de fevereiro de 2016. 
Encontrava-se distante do universo pensante da maioria da intelectualidade e dos jovens universitários brasileiros, preocupados com o papel da arte na conscientização das desigualdades sociais e na resistência do regime militar do país. Nas letras nada de rebeldia, sexo, drogas ou crítica social [...], misturava palavras adocicadas e histórias ingênuas ao ritmo agressivo das músicas. Apesar dessa ingenuidade aparente, as letras da Jovem Guarda potencializavam as primeiras manifestações do corpo como fonte de prazer para os adolescentes, e o amor, namoro, os beijos, a minissaia e a dança tornaram-se elementos de transgressão dos valores moralizantes da época dentro dos limites permitidos pela sociedade.

Contrariamente a essa percepção negativa da música brega, expressa-se em Belém uma massa de bregueiros que estabelecem relações de maior ou menor grau com esse estilo musical. Segundo Silva (1992, apud Costa, 2007), os sujeitos que de alguma maneira estão envolvidos com a música brega em Belém podem ser assim discriminados: 1ㅇ público cativo, que é aquele cujos sujeitos são de origem pobre e para os quais a música brega faz parte de uma apreensão total do universo sociocultural das pessoas; $2 \circ$ o público opcional, que é aquele que ouve e dança a música por opção, mas sem qualquer identidade com a música; e 3ㅇ, o público momentâneo de classe média, cuja relação com a música se dá de forma casual e para os quais, portanto, o brega não faz parte de seu universo sociocultural.

Essa classificação de identificações mais ou menos duráveis é ainda observável entre os sujeitos da população belenense. Vale ressaltar que, para este artigo, o nosso foco está no público cativo, ou seja, nos sujeitos que moram nas periferias de Belém, onde a música brega compõe um universo sociocultural, em especial jovens e adolescentes que expressam suas identidades bregueiras, principalmente nas festas dos bregões de Belém.

As festas de brega em Belém transcendem sua dimensão situacional, alcançando e marcando simbolicamente a cidade, em especial a sua periferia. Elas promovem sociabilidades juvenis e reforçam laços de uma identidade bregueira, ao mesmo tempo em que possibilitam rearranjos dessa identidade que se têm inovado no tempo e no espaço bregueiro de Belém (Costa, 2006; Damasceno, 2002 Favacho, 1995).

Assim, a festa é um dos principais elementos que compõem o universo bregueiro. É na festa dos bregões da cidade que se encontram todos os elementos que compõem esse universo. Em alguns casos, a festa tem a capacidade de agregar em um mesmo espaço e tempo, aparelhagem, DJ, cantores e os sujeitos adeptos da música, constituindo os pedaços característicos de identificação dos mesmos (Magnani, 1998).

Essa característica é marcante, sobretudo, nas festas de tecnobrega, que reúnem o uso intenso de tecnologia na composição das músicas, com o intuito de acelerar o ritmo com acréscimo de PIT; a adesão de um novo público - jovens e adolescentes - e a dança, que pode ser realizada por casais ou individualmente, com coreografias ousadas e frenéticas, nas quais o corpo torna-se sua maior expressão ${ }^{13}$.

Acredita-se que o PIT, pela sua capacidade em deixar a música mais acelerada e dançante, exigindo mais flexibilidade e agilidade do corpo, foi o grande propulsor da

13 Esse arranjo de elementos culturais mediados pela tecnologia produz e define uma situação característica do cenário tecnobrega, próxima daquilo que Vizer (2010) denominou de enraizamento social das tecnologias. 
"virada" ocorrida na música brega, que culminou com a chegada dos adolescentes nas festas, a partir do ano 2000, e se intensificou entre 2010 e 2011 com o TREME.

O corpo, portanto, passa a se configurar no estilo brega como um recurso decisivo na mudança ocorrida na música. Pois ele "[...] é o recurso mais imediato utilizado para modificar a relação do homem com o meio, o que possibilita uma reconfiguração de limites, permitido assim, ao indivíduo manipular as relações entre o eu e o outro, o dentro e o fora, o corpo e o mundo" (Le Breton, 2010 p. 26). Nesse sentido, o autor afirma que:

Para o adolescente, o corpo, enquanto representação da relação com o mundo, é simultaneamente o mundo interno e o mundo externo. Ele é, ao mesmo tempo, eu e não-eu, em suas mudanças, a sexualização que o atravessa, o sentimento de ser propriedade dos pais, etc. O corpo representa, então, o intermediário, um eu já alhures no mundo e um mundo já em si mesmo (Le Breton, 2010, p. 27).

Corpo, neste sentido, é percebido não apenas como um substrato biológico, mas também como suporte basilar para a existência da cultura e do sujeito. Assim, o corpo é tão essencialmente biológico quanto é essencialmente "[...] religioso, linguístico, histórico, cognitivo, emocional e artístico" (Csordas, 2008, p. 19), ou seja, o corpo,

[...] não é mais nem o corpo como mero instrumento, corpo significado, nem o corpo como lugar de inscrição [...] da cultura, mas é o corpo fenomênico, o corpo como locus da cultura, meio de sua experimentação do "fazer-se humano" em suas múltiplas possibilidades (Steil; Murillo, 2008, p. 11).

Dessa maneira, o corpo é entendido como a morada da cultura, a base necessária para que a cultura possa existir. Assim, nas festas de tecnobrega, o corpo fala, não com palavras, mas com movimentos que definem uma emergente identidade bregueira, que rompe fronteiras e limites, agregando novos elementos e valores, que se fazem mediados pela corporeidade dos jovens e adolescentes ao fazerem-se bregueiros.

\section{Do brega ao tecnobrega, ou do gosto popular ao estilo de vida outsider}

Nesse novo universo bregueiro, cuja identidade agora agregou o tecnobrega, os adolescentes e jovens das periferias de Belém se expressam por meio de estilos próprios. Eles possuem um jeito singular de se relacionar com a música e manifestam esse jeito por meio das roupas que usam, do corte de cabelo e da sobrancelha, e principalmente, da maneira como dançam ${ }^{14}$, elementos que se combinam na constituição de códigos de vestimenta, ou códigos corporais, das suas performances (Santamaría, 2006).

Os jovens bregueiros costumam usar roupas de marcas famosas, tais como: Pit Bull, Nike e Adidas. São poucos os que usam sapatos, preferem sandálias de dedos da

14 Esse jeito peculiar dos jovens bregueiros foi observado nas inúmeras vezes que estivemos nos bregões de Belém. Algumas dessas vezes estivemos como observadores, em outras, como bregueiros. 
Kener, que custam em média cem reais, enquanto que uma camisa das marcas supracitadas não custa menos que o preço da sandália, podendo chegar até duzentos reais. A calça ou bermuda custa em média de cem a quatrocentos reais ${ }^{15}$.

As jovens têm preferência por vestir roupas da Pit Bull. Uma calça desta marca custa em média trezentos reais e a blusa fica em torno de cem reais. Outras jovens preferem vestidos extremamente justos e curtos, e a marca para estas não importa. Já os sapatos, elas preferem aqueles de salto alto e da marca Melissa.

O cabelo é outra característica peculiar dos jovens bregueiros. Normalmente eles pintam o cabelo de loiro e fazem desenhos no couro cabeludo, na forma de linhas retas ou curvas, que se iniciam desde a testa e terminam aproximadamente na nuca. São normalmente duas ou três dessas linhas em cada lado da cabeça. As sobrancelhas desses jovens também têm características próprias, são marcadas por um ou dois cortes na vertical, mais ou menos no centro de cada sobrancelha. A tatuagem também compõe o estilo dos bregueiros, e, normalmente, trata-se da imagem de um sol tatuado em uma das mãos, entre o polegar e o indicador. Nesse sentido, as tatuagens enquanto "[...] marcas corporais são balizas identitárias, formas de inscrever limites na pele, e não apenas enquanto metáfora. A pele participa intensamente no processo de separação-individuação que caracteriza a passagem do adolescente" (Le Breton, 2010, p. 26).

Há, portanto, uma estilização daqueles que são adeptos do tecnobrega. O jeito próprio de ser bregueiro, no tecnobrega, é definido por um estilo de vida marcado por códigos de vestimenta e corporais, que constituem um estilo de vida, um projeto.

[...] em vez de adotarem um estilo de vida de maneira irrefletida, perante a tradição ou hábito, transformam o estilo num projeto de vida e manifestam sua individualidade e senso de estilo na especificidade do conjunto de bens, roupas, práticas, experiências, aparências e disposições corporais destinados a compor um estilo de vida (Featherstone, 1995, p. 123).

A maneira como os adolescentes e jovens se caracterizam, no tecnobrega, faz parte de um novo projeto que agora compõe o universo da música brega. A escolha ou decisão em aderir a esse projeto não ocorre de forma desinteressada e aleatória, antes, é um recurso pelo qual os e as jovens se mostram enquanto indivíduos, nesse universo.

Nessa perspectiva, Velho (1981), auxilia a entender que a identidade vai se constituindo em razão de um projeto que é sempre negociado com outras categorias ou tradições que têm a capacidade de, em um determinado campo de interação, atuar politicamente e assim agenciar recursos indenitários.

Ao evidenciar os elementos de um projeto, o autor mostra que os projetos não são descolados das experiências comuns dos indivíduos, ou seja, o projeto é a confirmação da condição de pertencimento do sujeito. Então, o fato do indivíduo viver numa coletividade e ter uma vida subjetiva, não significa que ele se auto atribua valor, uma vez que o self dos indivíduos se manifesta na experiência comum: "o self tem a característica de ser um objeto para si, e essa característica o distingue de outros

15 As marcas e os valores aqui descritos estão fundamentados numa pesquisa que fizemos em lojas de Belém, especializadas em venda de roupas e calçados das marcas aqui citadas e de outras. 
objetos" (Mead, 2003, p. 168). Ele é para "si mesmo", ao mesmo tempo sujeito e objeto. A classe de experiência que distingue essa objetivação para si, do self, pode ser apreendida na distinção entre as experiências envoltas por uma atividade exterior, orientadas por uma ação ou campo de coisas exteriores, e as experiências em que o indivíduo é o principal objeto, ativando memória e imaginação. Assim o self é e se expressa sempre em um processo de comunicação e na interação com outros.

Nesse sentido, não existe subjetividade pura, assim como não há projeto individual puro, ou seja, a construção de um projeto só é possível mediante a negociação com outros projetos. A particularização, a maneira de constituir a identidade na complexidade não anula, ao contrário, pode confirmar, como diria Goffman (1985), a afirmação de si que se faz por meio da confirmação da coletividade, e é esse processo que vai gerar, no caso dos e das jovens das periferias de Belém, a identidade bregueira, agora associada ao tecnobrega.

A questão colocada por Velho, na relação entre identidade e projeto, se dá em como o indivíduo pode dialetizar essa relação. Se, em contraste com os outros, o indivíduo tende a projetar aquilo que é afirmação de si em relação com a confirmação da comunidade, sob certas condições problemáticas, essa projeção pode se orientar para outra direção. A maneira como esse contraste se define, legitimando o projeto, dando-lhe condições, gerando recursos ou não, pode mudar a sua relação com uma identidade, ou pode mudar a sua relação com uma coletividade.

[...] os projetos mudam, um pode ser substituído por outro, podem se transformar. O mundo dos projetos é essencialmente dinâmico, na medida em que os atores têm uma biografia, isto é, vivem no tempo e na sociedade, ou seja, sujeitos à ação de outros atores e às mudanças sócio-históricas (Velho, 1981, p. 27).

É, portanto, na relação contrastiva que os indivíduos estabelecem com outros indivíduos, com outros projetos na vida contemporânea, que os projetos se fazem, isto porque, não há uma dimensão puramente estável e equilibrada, senão que, pela relação de contraste ou de associação com valores de outros projetos, outras coletividades e outras identidades, estes possam mover o indivíduo para direções diferentes, agregando significados e identidades diferentes.

O indivíduo, nesta perspectiva, é colocado frente a escolhas que se definem pela liberdade que ele manifesta para tanto. A delimitação de projetos específicos e individuais varia com a valorização do indivíduo como unidade real, ou como dimensão produzida culturalmente na ambiguidade, segundo certa organização dos sentimentos.

[...] mesmo dentro de uma sociedade específica - no caso, em função da classe social - pode haver forte variação quanto á ênfase e preocupação que é dedicada às peculiaridades, gostos, preferências, traços particulares dos agentes empíricos. Isso se associa não só a uma visão de mundo (ou um eidos) em que a noção de biografia é central [...], mas também a um ethos, um estilo de vida, uma organização das emoções em que a experiência do agente empírico sacralizada como individual é foco e referência básica. Coloca-se como problema a relação entre projetos individuais e os círculos sociais em que o agente se inclui ou participa. A ideia central é que primeiramente, reconhece-se não existir um projeto individual "puro", sem referência ao outro ou ao social. Os projetos são elaborados e cons- 
truídos em função de experiências sócio-culturais, de um código, de vivências e interações interpretadas (Velho, 1981, p. 26).

A concepção de projeto defendida por Velho (1981) está assentada na noção de que os indivíduos escolhem ou podem escolher coisas diferentes, mesmo dentro de normas e padrões. Assim, o autor afirma que, situado em um campo de possibilidades, o projeto deve se expressar em uma linguagem para o outro e pode se transformar a partir de experiências biográficas, sempre se referindo a outros projetos e condutas localizadas no tempo e no espaço, de acordo com as redes abertas ou fechadas ao movimento dos sujeitos.

A proposição de Velho (1981), ajuda a entender os processos pelos quais o universo bregueiro de Belém tem passado, mudando assim o perfil, o gosto, o jeito de vestir e dançar, mudando a forma dos sujeitos se relacionarem com esse universo, até o momento em que o brega se transforma em tecnobrega. Tecno de tecnologia, mas também de profundas transformações nos projetos daqueles que vivem em um processo de interação mediado e impulsionado pela música, a projetar uma outra maneira de ser bregueiro em Belém. Nesse contexto de mudança do brega ao tecnobrega projeta-se, supomos, um estilo de vida configurado pela apropriação dos produtos acima identificados.

Isto nos permite entender que

Os projetos constituem, portanto, uma dimensão da cultura, na medida em que sempre são expressões simbólicas. Sendo conscientes e potencialmente públicos, estão diretamente ligados à organização social e aos processos de mudança social. Assim, implicando relações de poder, são sempre políticos (Velho, 1981, p. 34).

Nessa perspectiva, as festas de tecnobrega são marcadas por essas características. Nelas, a presença de jovens que se reúnem para dançar e se divertir expõe também buscas de prestígio, status e poder, que são definidos pela performance que os jovens desempenham, através da ostentação.

As roupas de marcas famosas e caras, além de compor a identidade bregueira desses sujeitos, também definem status dentro das festas. Os jovens que usam roupas mais famosas e caras são os que detêm mais prestígio e legitimidade no universo do tecnobrega. Tal prestígio é reconhecido principalmente pela quantidade das jovens que eles atraem para suas mesas e de cervejas que eles dispõem.

A ostentação configura-se uma das marcas dessa identidade bregueira, na qual a vestimenta e a quantidade de cervejas disposta na mesa são recursos e suportes de marcação social, impulsionando uma competição entre os jovens, isoladamente, e entre equipes ${ }^{16}$ de jovens. Essa competição acaba por definir quais jovens ou equipes têm mais prestígio, e o parâmetro para essa definição é a capacidade que os mesmos têm de conquistar e agregar em suas mesas o maior número de meninas.

Essa ostentação dos bregueiros, nas festas, é questionada por sujeitos não bregueiros, através de um sistema de acusação que rotula e estigmatiza esses jovens, associando o uso das roupas e sapatos caros, e a extravagância do consumo de cer-

16 Equipes são denominações dadas aos grupos de adolescentes e jovens adeptos do universo bregueiro, que se organizam em grupos como se fossem Fãclubes de aparelhagens. Cada equipe tem um nome e são rivais dentro da festa. A rivalidade se dá apenas na capacidade de ostentar que cada equipe possui. 
vejas, a atos marginais e desviantes, como roubos, furtos e comercialização de entorpecentes. Essa ostentação seria, então, produto da conduta desviante dos jovens, conforme afirmou a delegada de polícia entrevistada.

Há uma relação direta dos atos infracionais cometidos pelos menores infratores que cumprem medidas socioeducativas nas casas de recuperação aqui de Belém, com o universo bregueiro, em especial com a festa de tecnobrega. Esses jovens, com o intuído de consumir roupas de marca, acabam por cometer delitos como furto, roubo e até tráfico de entorpecentes, porém dentre esses delitos o mais comum é o roubo. Para roubar eles se organizam em grupos e cada indivíduo colabora com uma determinada quantia para comprar a arma de fogo. Então a arma fica sendo propriedade do grupo. Noutras situações o indivíduo aluga a arma para roubar. Eles praticam esses delitos para adquirir as vestes e depois se exibirem nas festas de tecnobrega, de aparelhagem (Entrevista concedida em 1 de fevereiro de 2015).

Além da condição supracitada, os jovens bregueiros também são estigmatizados, em seu estilo peculiar, pelo cabelo pintado de loiro, um traço visível dos bregueiros e fortemente disseminado em Belém. Nesse sentido, há certo consenso nos discursos de rotulação desses jovens nos segmentos sociais da cidade, que acabam por ser representados pela afirmação da delegada:

O estilo define esse jovem como infrator. Quase todos os jovens infratores são loirinhos. Se numa abordagem tivermos dois grupos de adolescentes, um grupo de loiros e outro não loiros, certamente nosso foco será no primeiro grupo. $\mathrm{O}$ cabelo loiro e a roupa de marca acabam por lhes definir como marginais. E são! ${ }^{17}$ (Entrevista concedida em 1 de fevereiro de 2015).

Assim rotulados, os jovens bregueiros são classificados em categorias de grupos desviantes que, segundo Santamaría (2006, p. 2),

Ya sea como grupos que se piensan vinculados de manera marginal o central con diversas manifestaciones del crimen organizado [...] o como delincuentes que amenazan los espacios más locales a través del robo [...] ocupan un lugar prioritario tanto en la mente de los habitantes de comunidades y barrios, como en las agendas de los tomadores de decisión.

Ocorre que, na definição de desvio atribuída a esses sujeitos, assim como propôs Becker (2008), não é necessariamente o delito que deve ser focado, senão, a própria delimitação do desvio. A proposição do autor nos leva a um problema que, segundo ele, é muito mais geral que o ato de cometer um delito, uma vez que nos permite;

[...] olhar para todos os tipos de atividades, observando que em toda parte pessoas envolvidas em ação coletiva definem certas coisas como "erradas", que não devem ser feitas, e geralmente tomam medidas para impedir que se faça o que foi assim definido. De forma alguma essas atividades serão todas criminosas (Becker, 2008, p. 13).

É o interesse de Becker pelo cotidiano que faz emergir então a necessidade de outra teoria para entender o desvio, que não aquela centrada na natureza, ou na qualidade do ato, e é nessa perspectiva que buscamos entender os adolescentes e jovens

17 Estas afirmativas da delegada são, segundo ela, fundamentadas em sua experiência enquanto delegada de polícia na DATA. 
bregueiros de Belém.

Para Becker, outsider é aquele indivíduo que vive em desacordo com as regras estipuladas por um grupo, ou seja, o autor usa o termo,

[...] para designar aquelas pessoas que são consideradas desviantes por outras, situando-se por isso fora do círculo dos membros "normais" do grupo. Mas o termo contém um segundo significado, cuja análise leva a um outro importante conjunto de problemas sociais: "outsiders", do ponto de vista da pessoa rotulada de desviante, podem ser aquelas que fazem as regras de cuja violação ela foi considerada culpada (Becker, 2008, p. 27).

Aqui, a rotulação pode ter mão dupla, ou seja, na ausência de legitimação ou competência daquilo que é rotulado e de quem rotula, aquele que foi rotulado pode chamar quem rotula de outsider. Então, na análise da situação de imposição e transgressão das regras e dos processos pelos quais algumas pessoas vêm a infringir regras e outras a impô-las, interessa para o autor reconhecer o que ele chama de regras operantes efetivas. Ou seja, não é qualquer regra que ajuda a entender o desviante. Isto porque certas regras podem ser percebidas, mas não seguidas.

A questão básica aqui é: quando é que uma regra se torna operante e efetiva dentro de um grupo? Existem regras que valem para uns grupos, mas para outros não. É a reação do grupo que vai determinar se um dado ato é desviante ou não. Nesse sentido, a situação e a reação constituem o princípio da transgressão.

Segundo Becker (2008), duas perspectivas atuam na definição do desvio: a maior ou menor proximidade com a identidade que partilhamos e a maior ou menor proximidade com as concepções de justiça que partilhamos; ou seja, a legitimação de uma norma frente a uma regra é o que a define.

Desde essa perspectiva, na análise das definições de desvio é importe considerar o limite das características do ato desviante e dos desviantes, e buscar superar esses limites pela consideração de situações e processos de julgamento que são variáveis. Três definições de desvios seriam predominantes: o desvio medido pela estatística em relação à média, que deixa de lado muitas questões de valor sobre a natureza do desvio; o desvio como patologia, ou doença, que deixa de lado o que as pessoas consideram que constitui um comportamento saudável; e o desvio que o autor chama de relativista, que diz respeito ao não cumprimento das regras do grupo.

Tanto do ponto de vista estatístico quanto da perspectiva patológica, o desvio está situado no indivíduo e, ao analisar o desvio, não se considera quem o julga, nem tão pouco quem é o desviante. Segundo o autor, as estatísticas operam com a justificativa de mostrar a probabilidade dos atos, o que acaba por esconder a improbabilidade. O fato de tal coisa poder acontecer é quase sempre escondido pela estatista, quando estabelece pela média o que acontece. $O$ problema aqui é desconsiderar que a probabilidade ou a improbabilidade dos atos desviantes acontecerem varia com a definição da função de um grupo (seus traços funcionais e disfuncionais) que é decidida na política. Dessa forma, os dados estatísticos que indicam a probabilidade de os atos delituosos serem praticados por jovens de periferia são projetados em decisões políticas que homogeneízam as formas com que os dispositivos das políticas públicas tratam grupos periféricos de jovens, como os bregueiros. 
Já a definição relativista entende o desvio como falha em obedecer às regras do grupo. Nesse caso, há ausência de consideração das ambiguidades produzidas pela pertença a vários grupos, ou seja, quando o indivíduo relativiza a questão do desvio como falha em obedecer às regras, já que as regras de um grupo podem não valer para outros e, ao contrário, o que é regra em um grupo pode não ser em outro, o que aqui é proibido, lá pode ser tolerado e até incentivado.

Isto pode ser aplicado aos adolescentes e jovens bregueiros, que participam de outros grupos fora do universo bregueiro, fato desconsiderado nos processos de rotulação e acusação, como no relato da delegada de que, em uma abordagem policial de dois grupos de jovens, o foco estará nos loirinhos. Há, portanto a necessidade de se entender as ambiguidades dessa pertença do ator a vários grupos, o que inclusive interfere no reconhecimento probabilístico dos possíveis atos desviantes.

A associação de fatores como "ser de periferia", "ostentar roupas" e "consumir muitas bebidas", no discurso e nos processos de rotulação dos bregueiros como desviantes, estaria dessa forma delimitando e aproximando categorias de percepção social que são consideradas excludentes, quando discriminadas segundo um regime de valor estabelecido e atribuído a estilos de vida. Assim, a retradução de diferenças objetivamente inscritas nas condições de existência de segmentos sociais diferenciados, como definições sociais e distinções entre luxo e necessidade, passa pelo crivo social das formas de apropriação: a propensão ou aptidão dos bregueiros ao roubo.

Nessa retradução, desviante é aquele que as pessoas rotulam como tal pela aplicação de regras e sanções. Assim, afirma Becker que (2008, p. 21 e 22):

[...] grupos sociais criam desvios ao fazer as regras cuja infração constitui o desvio, e ao aplicar essas regras a pessoas particulares e rotulá-las como outsiders. Desse ponto de vista, o desvio não é uma qualidade do ato que a pessoa comete, mas uma consequência da aplicação por outros de regras e sanções a um infrator. O desviante é alguém a quem esse rótulo foi aplicado com sucesso; o comportamento desviante é aquele que as pessoas rotulam como tal.

Se essa definição pode gerar subordinação quando associada a valores velados, ou preconceitos, isso se percebe quando o produto dos processos de rotulação e acusação resultam em estereótipos sociais, como o de que "bregueiro é ladrão".

E aqui, considerando a indicação de Becker (2008), de que a definição de uma transgressão deve ser referida como comportamento de violação de regra, e não como desvio, complementada pela reação dos outros em relação ao "desviante" e ao "desvio" por ele cometido, compreende-se que "o desvio não é uma qualidade simples, presente em alguns tipos de comportamento e ausente em outros. É antes o produto de um processo que envolve reação de outras pessoas ao comportamento." (2008 p. 26).

Há que considerar, nessa perspectiva, que no processo pelo qual a rotulação se produz emergem fatores normatizadores da ação individual e coletiva: os comportamentos considerados apropriados e desapropriados, sobre os quais, inclusive, a característica básica do agir da lei é aquela pela qual os policiais prendem sob suspeição. Complementar a essa normatização, entretanto, os códigos de vestimenta e corporais partilhados e expostos pelos bregueiros, nesse processo, também faz 
emergir um campo dialético que tensiona políticas identitárias, em conformidade com a análise de Csordas (2008, p. 22), em que se deve

[...] distinguir de forma mais clara entre uma política pessoal de identidade coletiva, na qual atores individuais com compromissos claros lutam para afirmar uma identidade compartilhada, e uma política coletiva de identidade pessoal, na qual cada ator em um grupo de atores com compromissos ambíguos luta para obter uma identidade individual.

Por fim, esses tipos teórico-descritivos permitem considerar os comportamentos e reações que evocam suas semelhanças e diferenças, em cada situação específica: de um lado, a rotulação da ostentação como luxo e desvio; de outro, a manifestação da ostentação como estilo de vida que tensiona a ideia de luxo, enquanto gosto ou estilo de vida de poucos.

\section{Considerações finais}

Ser brega em Belém, no sentido tratado neste artigo, é ser adepto de um estilo musical que se constituiu na cidade entre os anos 1970 e 80 . Inicialmente, esse estilo caiu no gosto daqueles sujeitos que habitam a periferia de Belém, mas, com o tempo, teve a adesão de outros segmentos da cidade, transformando-se em um movimento. Nesse movimento, existem aqueles cuja música compõe seu universo sociocultural, o que colaborou para a produção de uma identidade bregueira na periferia de Belém, como estilo de vida.

A questão discutida aqui foi a de que o advento do tecnobrega, impulsionado pela inclusão mais intensa das aparelhagens nas festas, provocou profundas transformações na maneira como os adeptos se relacionam com o universo bregueiro, 0 que culminou com a adesão de adolescentes e jovens que passam a projetar e manifestar outra identidade no movimento, agora marcada por códigos corporais e de vestimenta no seu jeito de ser. Isto acabou por imputar nesses adolescentes e jovens rótulos que lhes definem como sujeitos desviantes, infratores, outsiders.

Os rótulos atribuídos aos bregueiros fundamentam-se na maneira como esses rapazes se apresentam nas festas e na sociedade. Roupas e calçados de marcas, cabelo pintado de loiro, sobrancelha com traços, são características que os definem como bregueiros, além das performances individuais e em equipes nas festas, que se caracterizam por atitudes de ostentação. Esta ostentação sustenta um estilo que é comunicado por esses sujeitos - a maneira como eles querem ser vistos enquanto bregueiros - mas é apreendida socialmente segundo modos de produção de políticas de identidade que constituem quadros normatizadores da ação individual e coletiva dos mesmos.

Assim, buscamos evidenciar que a associação socialmente estabelecida entre luxo e ostentação, frente à condição periférica dos jovens bregueiros de Belém, ao ser relacionada a formas delituosas de apropriação dos mesmos, desconsidera o caráter tensionador da política de identidade que os bregueiros expõem, ao combinar arranjos de vestimentas e corporais na explicitação de sua presença, seja nas festas tecnobrega, seja no cotidiano da cidade. 


\section{Referências}

ARANTES, Antônio Augusto. O que é cultura popular. São Paulo: Brasiliense, 1990.

BECKER, Howard S. Outsiders; estudos de sociologia do desvio. Rio de Janeiro: Jorge Zahar Editor, 2008.

BOURDIEU, Pierre. Gostos de classe e estilos de vida. In: ORTIZ, Renato (org.) Bourdieu (Coleção Grandes Cientistas Sociais) São Paulo: Ática, 1999. p. 82-121.

BRANDÃO, Antônio Carlos et al. Movimentos Culturais e Juventude. São Paulo: Moderna, 1990.

CALDAS, Waldenyr. A utopia do gosto. São Paulo: Brasiliense, 1988.

CSORDAS, Thomas J. Corpo/Significado/Cura. Porto Alegre: Ed. Da UFRGS. 2008.

COSTA, Antônio M. D. A festa dentro da festa: recorrências do modelo festivo do circuito bregueiro no Ciro de Nazaré em Belém do Pará. Campos, Curitiba, Vol. 7, no 2, p. 83-100, 2006.

Festa na cidade: o circuito bregueiro de Belém do Pará. Belém: Art Impressa, 2007.

DAMASCENO, et al. A linguagem do Brega: presente e passado. Belém: EdUFPA, 2002. LE BRETON, David. Escarificações na adolescência: uma abordagem antropológica. Horizontes Antropológicos, Porto Alegre, Ano 16, no 33, p. 25-40, jan./jun. 2010.

ERGUR, Ali. Le rôle des nouvelles technologies dans la construction des stratégies identitaires des jeunes des quartiers populaires d'Istanbul. Civitas, Porto Alegre, Vol.9, no 1, p. 87-102, jan.-abr. 2009.

FAVACHO, Paulo Afonso Cardoso. Nos embalos do sonzão: música e identidade cultural em Belém. Belém, 1995. (Trabalho de conclusão de curso em História) - Universidade Federal do Pará.

FEATHERSTONE, Mike. Cultura de consumo e pós-modernismo. São Paulo: Studio Nobel, 1995.

GODELIER, Maurice. Hierarquias nas sociedades primitivas e Antropologia Econômica. In: AGUIAR, Neuma (Org.) Hierarquias em classes. Rio de Janeiro: Zahar Editores, 1969, p. 77-94.

GOFFMAN, Erving. A Representação do Eu na Vida Cotidiana. Petrópolis, Vozes, 1985. 
MAGNANI, José Guilherme. Festa no pedaço; o circo-teatro e outras formas de lazer e cultura popular. São Paulo: Hucitec, 1998.

MEAD, George H. Espíritu, persona y sociedad. Buenos Aires: Paidós, 2003.

MORAES, Maria José. Entrevista concedida a Miguel de Nazaré Brito Picanço e José Rogério Lopes. Belém-Pa,1 de fevereiro de 2016.

PICANÇO, Miguel de Nazaré Brito. Brega: cultura popular e identidade em Belém. Castanhal-Pará, 2004. (Trabalho de conclusão de curso em Ciências Sociais): Universidade Federal do Pará.

SANTAMARÍA, Gema. Las maras centro-americanas, una identidad que ha dejado de tatuarse: posibles lecciones para las pandillas mexicanas. CEPI Documento de trabajo, México, no 9, 2006.

STEIL, Carlos Alberto e MURILLO, Luís Felipe Rosado. Apresentação. In: CSORDAS, Thomas J. Corpo/Significado/Cura. Porto Alegre: EdUFRGS, 2008, p. 9-13.

VELHO, Gilberto. Projeto, emoção e orientação em sociedades complexas. In: Individualismo e Cultura. Notas para uma Antropologia da Sociedade Contemporânea. Rio de Janeiro: Zahar, 1981, p. 13-37.

VIZER, Eduardo A. A trama (in)visível da vida social: comunicação, sentido e realidade. Porto Alegre: Sulina, 2010.

Recebido em: 05/09/2016

Aprovado em: 11/11/2016 